\title{
Effects of salinity and cadmium interaction on reproduction and growth during three successive generations of Ophryotrocha labronica (Polychaeta)
}

\author{
K. H. Røed* \\ Institutt for marin biologi og limnologi, Avd. marin zoologi og marin kjemi, \\ Universitetet i Oslo; P.B. 1064, Blindern, Oslo 3, Norway
}

\begin{abstract}
The long-term effects of different cadmium (0.2 and $0.4 \mathrm{ppm})$ and salinity levels (30, 25 , and $20 \%$ S) on growth and egg-mass production of Ophryotrocha labronica (La Greca \& Bacci) were investigated over three generations. Low salinity levels and the presence of cadmium resulted in reduced growth rates, prolonged times to reach sexual maturity, and reduced size at maturity. Three-way analysis of variance showed significant interaction effects of generation and cadmium for the different growth processes tested. Using response-surface methods, $0.2 \mathrm{ppm}$ cadmium was shown to have a greater effect on growth rate at the third generation than the first and second generations at the three salinities tested. Increased effects were observed from first to second generation at $0.4 \mathrm{ppm}$ cadmium and 30 and $25 \% \mathrm{~S}$, whereas effects decreased from second to third generation. At $0.4 \mathrm{ppm}$ cadmium and salinity of $20 \%$ the first generation was not able to produce viable larvae.
\end{abstract}

\section{INTRODUCTION}

The effect of different heavy metals on marine life has been extensively studied in recent years (cf. Waldichuk, 1974). Elevated concentrations of heavy metals are usually restricted to confined localities, largely associated with industrial development (Preston, 1973), particularly in estuaries. One of the chief characteristics of estuaries is the large number and range of seasonal environmental variables. It is of great importance to know how these normal environmental fluctuations interact with pollutants in their effects on organisms.

Information on the effect of toxic heavy metals in estuaries has mostly been directed towards assessing lethal levels of single pollutants but comparably little is known of the interaction of pollutant and environmental fluctuations. However, Perkins (1974) has stressed that mortality of organisms in standard tests is a poor toxicity criterion. Therefore, sublethal concentrations must also be examined. In their study of pollution effects on micro- and meiofauna of sand, Gray \& Ventilla (1971) pointed out that growth-rate studies are more reliable bioassays than $\mathrm{LC}_{50}$-tests. Accordingly, the present study was undertaken to evaluate the effects of interacting sublethal concentrations of salinity and cadmium on growth and reproduction of the polychaete Ophryotrocha labronica, which

* Present address: Agricultural University of Norway, Department of Zoology, Box 46, 1432 AasNLH, Norway 
Åkesson (1970) has suggested as a possible test animal for pollutant studies. The multivariate experiments were undertaken over three generations and interactions were examined at each generation.

\section{MATERIAL AND METHODS}

The Ophryotrocha labronica used was from the Naples strain and had been cultured in the laboratory at $30 \%$ and $20 \pm 2{ }^{\circ} \mathrm{C}$ for several years (Akesson, 1970). The size of the adults is about $3-3.5 \mathrm{~mm}$ and, at ordinary room temperature, its life cycle is completed in less than one month. The species is gonochoric and a single female produces a new egg mass with 100-150 eggs every fortnight during a period of at least three months.

In the $48-\mathrm{h} \mathrm{LC}_{50}$-test a temperature of $20 \pm 2{ }^{\circ} \mathrm{C}$ was maintained in glass bowls containing $50 \mathrm{ml}$ of seawater (salinity of $30 \%$ ) which was aged, filtered and sterilized by heating to $80^{\circ} \mathrm{C}$ for $24 \mathrm{~h}$. To these bowls $2,3,3.5,4,4.5,5,6$, and $7 \mathrm{ppm}$ cadmium $\left(\mathrm{CdCl}_{2}\right)$ were added. Five males and five females were used in each bowl and were fed spinach ( $\AA$ kesson, 1970) initially in excess. After $48 \mathrm{~h}$ the surviving individuals were counted. Paralyzed individuals were transferred to clean seawater and those which did not recover after $24 \mathrm{~h}$ were considered dead. Each experiment was duplicated. The mean percent mortalities of the 48 - $\mathrm{h} \mathrm{LC}_{50}$-tests were transformed from a sigmoid dosage mortality curve to a straight line using probits (Fisher \& Yates, 1963).

In order to obtain a sufficient number of newly released larvae of the same age (necessary for long-term experiments), synchronized spawings were obtained by isolating sexually mature males and females for about a week. When the sexes were reunited, most females spawned overnight.

The experimental design for the long-term experiment was $3 \times 3$ (cadmium $\times$ salinity) factorial design. The concentrations used were $5 \%$ and $10 \%$ of the $\mathrm{LC}_{50}$-value at salinities 30,25 , and $20 \%$. Newly released larvae (20-30 individuals) were transferred to each of the nine $100-\mathrm{ml}$ bowls (first generation). At intervals of $3-4$ days the number of segments with parapodia was determined on four individuals selected at random. After 15-20 days, when it was possible to distinguish the gender, five males and five females were picked out for further developmental studies. Segments with parapodia were thereafter counted on two males and two females selected at random. The fate of the twelve first egg masses was recorded during subsequent observations and the percent egg masses which hatched and gave vital larvae were calculated.

Larvae of the same age (second generation) were transferred from each concentration to new bowls with identical concentrations of cadmium and salinity to that used in the first generation. Measurements and counts were made following the same procedure used with the first generation for this and the third generation. However, at salinity of $20 \%$ and $0.4 \mathrm{ppm}$ cadmium (the extreme condition), the egg masses from the first generation did not hatch or the larvae died soon after hatching; no results were obtained under these conditions for the second and third generation. The experiments were duplicated and carried out at ordinary room temperature $\left(20 \pm 2{ }^{\circ} \mathrm{C}\right)$; the organisms were fed spinach and the experimental waters were changed every 10-12 days. Chemi$\mathrm{cal}$ analysis in a preliminary test showed that cadmium concentration, in 0.4 and $0.2 \mathrm{ppm}$ solutions kept at room temperature, did not change significantly (less than $10 \%$ ) after a period of 10 to 12 days. 


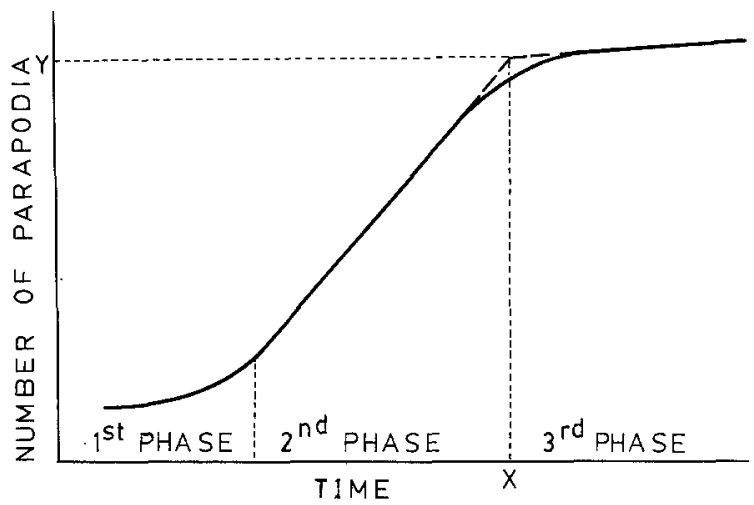

Fig. 1. Schematic illustration of idealized growth curve of Ophryotrocha labronica showing the three growth phases; time $(\mathrm{y})$ and size $(\mathrm{x})$ at maturity are extrapolated

The number of segments with parapodia was plotted against time and the curves obtained were divided into three phases (see the schematic illustration in Fig. 1). In the first phase ("lag" phase) there is no or little increase in the number of parapodia. The second phase (growth proper) shows an approximately linear increase in the number of segments with parapodia and the slope of this line was used as an expression for the individual growth rate. The third phase also shows a linear trend but with a shallower slope, and the point at which this extrapolated straight line cuts the line representing growth rate is defined as the time when the organisms reached maturity. This time interval and the size (as number of segments with parapodia) at maturity are extrapolated in Figure 1.

Analysis of variance was done following the methods of Davies (1963). Because no results were obtained from the second and third generations at salinity of $20 \%$ with the highest cadmium concentration, the analysis of variance was split into $3 \times 3 \times 2$ and $3 \times 2 \times 3$ (generation $\times$ cadmium $\times$ salinity) factorial design.

The growth-rate data at the three generations were analysed by response-surface methodology using a second degree polynomial equation of the form.

$$
\mathrm{Y}=\mathrm{b}_{0}+\mathrm{b}_{1} \mathrm{~S}+\mathrm{b}_{2} \mathrm{Cd}+\mathrm{b}_{11} \mathrm{~S}^{2}+\mathrm{b}_{22} \mathrm{Cd}^{2}+\mathrm{b}_{12} \mathrm{SCd}
$$

where $\mathrm{Y}=$ the estimated individual growth rate, $\mathrm{S}=$ salinity, and $\mathrm{Cd}=$ cadmium. The values of salinity and cadmium were replaced by polynomial multipliers $(-1,0,+1)$ and the equations shown are in terms of multipliers and not the values of salinity and cadmium. Such transformation greatly simplifies statistical calculations. In calculating the equations for the second and third generations where no results were obtained at $20 \% \mathrm{~S}$ with the highest cadmium concentration, the growth rate was set at zero.

\section{RESULTS}

\section{Effects on growth rate}

The toxicity of cadmium to Ophryotrocha labronica was found to give a 48 -h $\mathrm{LC}_{50^{-}}$ value of $4 \mathrm{ppm}$ (Fig. 2). Thus, 0.2 and $0.4 \mathrm{ppm}$ cadmium concentrations representing $5 \%$ and $10 \%$ of the $\mathrm{LC}_{50}$-value were used in the long-term experiment. 


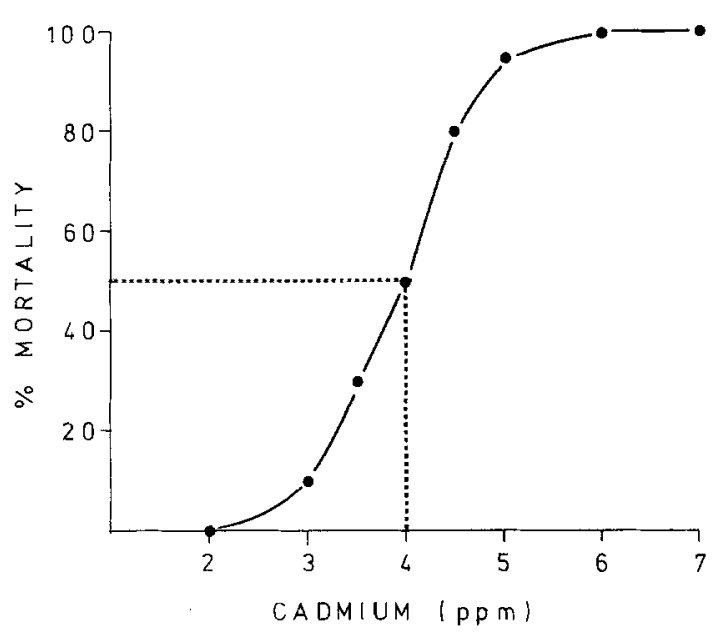

Fig. 2. 48-h mortality $\left(\mathrm{LC}_{50 / 48}\right)$ as function of cadmium at $30 \% \mathrm{~S}$ on adult Ophryotrocha labronica
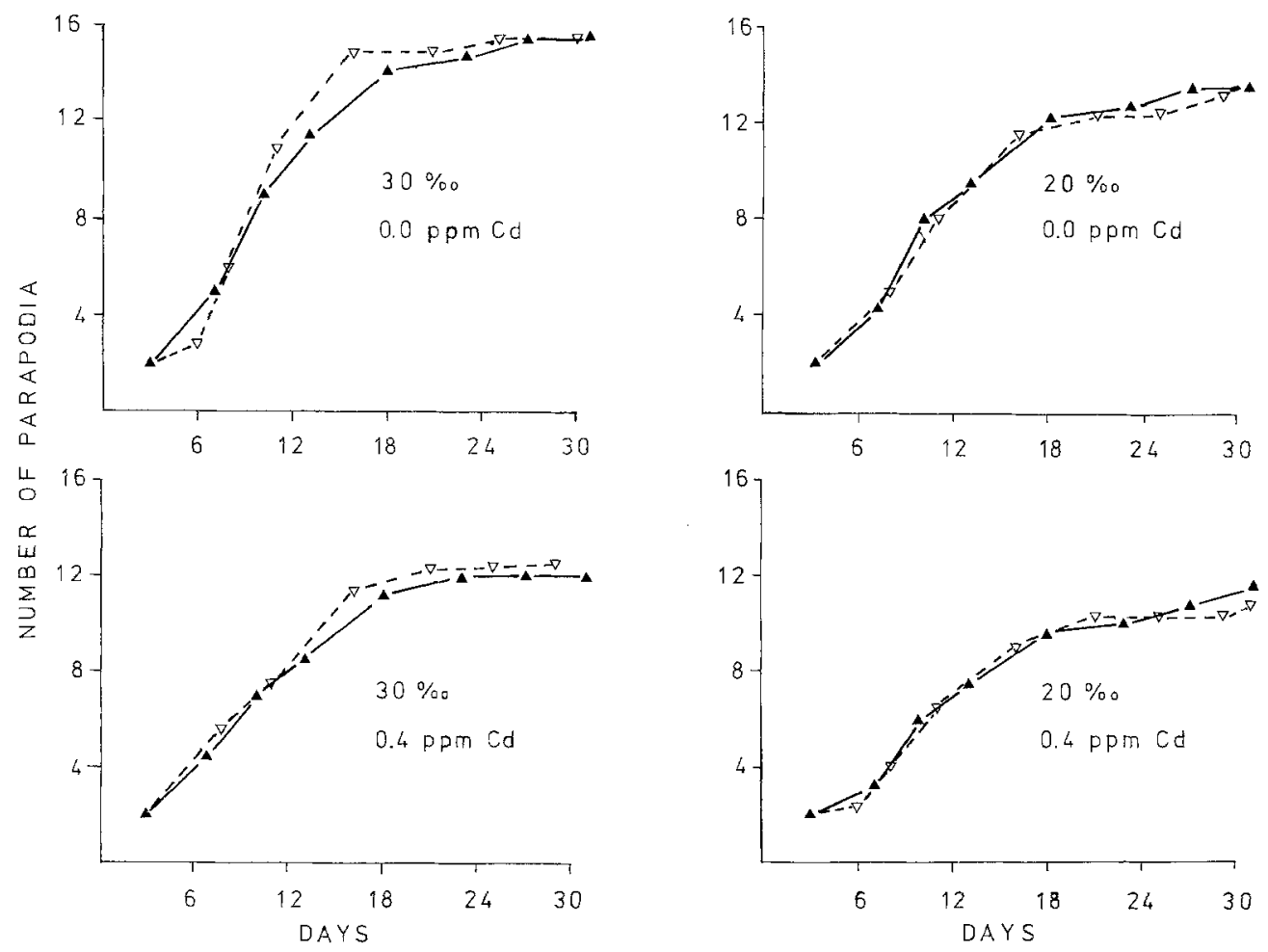

Fig. 3. Effects of reduced salinity and $0.4 \mathrm{ppm}$ cadmium on the individual growth curve of Ophryotrocha labronica. In each case curves from the two replicates are given (indicated by different symbols) 
Figure 3 illustrates the growth curve of the first generation in four of the nine combinations tested. It shows reduced growth rate (change in slope) both at reduced salinity $(20 \%)$ and at $0.4 \mathrm{ppm}$ cadmium concentration. The individual growth rates for all three generations over factorial design are given in Table 1. Table 2 shows the threeway analysis of variance of these data. The differences between the main effects were statistically significant. The effects of generation and salinity were only significant when the values of all the three salinities and cadmium concentrations of 0.0 and $0.2 \mathrm{ppm}$

Table 1. Relative growth rate (increase in number of parapodia versus time) at various combinations of cadmium and salinity at three generations of Ophryotrocha labronica (means of two replicates)

\begin{tabular}{|c|c|c|c|c|c|c|c|c|c|}
\hline Generation & \multicolumn{3}{|c|}{0} & \multicolumn{3}{|c|}{$\begin{array}{c}\text { Cadmium (ppm) } \\
0.2 \\
\text { Salinity }(\% \circ)\end{array}$} & \multicolumn{3}{|c|}{0.4} \\
\hline $1^{\text {st }}$ & 1.09 & 1.00 & 0.86 & 1.00 & 0.97 & 0.80 & 0.72 & 0.79 & 0.66 \\
\hline $2^{\text {nd }}$ & 1.06 & 1.07 & 0.91 & 1.00 & 1.02 & 0.74 & 0.52 & 0.51 & \\
\hline $3^{\text {rd }}$ & 1.03 & 0.96 & 0.84 & 0.92 & 0.70 & 0.48 & 0.79 & 0.73 & \\
\hline
\end{tabular}

Table 2. Three-way analysis of variance of data of the different growth processes and percent hatched egg masses of Ophryotrocha labronica. $\mathrm{A}=3 \times 3 \times 2$ and $\mathrm{B}=3 \times 2 \times 3$ (generation $[\mathrm{G}] \times$ cadmium $[\mathrm{Cd}] \times$ salinity $[\mathrm{S}])$ factorial design. $\mathrm{L}=$ linear, $\mathrm{Q}=$ quadratic. Significant $(\mathrm{p} \leqslant$ $0.05)$ effects marked

\begin{tabular}{|c|c|c|c|c|c|c|c|c|}
\hline \multirow{2}{*}{ Factors } & \multicolumn{2}{|c|}{ Growth rate } & \multicolumn{2}{|c|}{ Time } & \multicolumn{2}{|c|}{ Size } & \multicolumn{2}{|c|}{ Hatched egg masses } \\
\hline & A & B & A & B & A & B & A & B \\
\hline $\mathrm{G}_{\mathrm{L}}$ & 3.376 & $11.656^{*}$ & $9.582^{*}$ & $15.027^{*}$ & 0.953 & 0.330 & 1.468 & 0.846 \\
\hline $\mathrm{G}_{\mathrm{Q}}$ & 0.669 & $5.629^{*}$ & $66.156^{*}$ & $7.055^{*}$ & $9.080^{*}$ & 1.761 & $15.274^{*}$ & $13.928^{*}$ \\
\hline $\mathrm{Cd}_{\mathrm{L}}$ & $81.659^{*}$ & $18.011^{*}$ & $115.341^{*}$ & $33.388^{*}$ & $23.510^{*}$ & $35.177^{*}$ & $81.452^{*}$ & $20.650^{*}$ \\
\hline $\mathrm{Cd}_{\mathbf{Q}}$ & $5.038^{*}$ & & $25.519^{*}$ & & $12.795^{*}$ & & 3.924 & \\
\hline $\mathrm{S}_{\mathrm{L}}$ & 1.589 & $40.880^{*}$ & 0.149 & $17.449^{*}$ & 1.351 & $44.202^{*}$ & $4.476^{*}$ & $46.309^{*}$ \\
\hline $\mathrm{S}_{\mathrm{Q}}$ & & 3.269 & & 1.653 & & $9.488^{*}$ & & $6.005^{*}$ \\
\hline $\mathrm{Cd}_{\mathrm{L}} \mathrm{S}_{\mathrm{L}}$ & 0.366 & 1.941 & 0.782 & $8.347^{*}$ & 0.549 & $7.927^{*}$ & 1.141 & 0.469 \\
\hline $\mathrm{Cd}_{\mathrm{Q}} \mathrm{S}_{\mathrm{L}}$ & 0.648 & & 0.075 & & 0.122 & & 0.164 & \\
\hline $\mathrm{Cd}_{\mathrm{L}} \mathrm{S}_{\mathrm{Q}}$ & & 0.102 & & 3.780 & & 2.910 & & 0.020 \\
\hline $\mathrm{G}_{\mathrm{L}} \mathrm{S}_{\mathrm{L}}$ & 1.672 & 1.192 & 0.016 & $7.073^{*}$ & 0.409 & 0.427 & 1.288 & 0.069 \\
\hline $\mathrm{G}_{\mathrm{Q}} \mathrm{S}_{\mathrm{L}}$ & 1.007 & 0.477 & 2.023 & 3.912 & 0.412 & 0.614 & 0.058 & 0.003 \\
\hline $\mathrm{G}_{\mathrm{L}} \mathrm{S}_{\mathrm{Q}}$ & & 0.204 & & 0.011 & & 0.001 & & 0.696 \\
\hline $\mathrm{G}_{\mathrm{Q}} \mathrm{S}_{\mathrm{Q}}$ & & 1.567 & & 3.993 & & $5.984^{*}$ & & 0.230 \\
\hline $\mathrm{G}_{\mathrm{L}} \mathrm{Cd}_{\mathrm{L}}$ & 0.293 & $5.618^{*}$ & 0.273 & $18.543^{*}$ & 3.000 & 2.432 & 0.304 & 1.752 \\
\hline $\mathrm{G}_{\mathrm{L}} \mathrm{Cd}_{\mathrm{Q}}$ & 3.084 & & $4.550^{*}$ & & 0.444 & & 0.365 & \\
\hline $\mathrm{G}_{\mathrm{Q}} \mathrm{Cd}_{\mathrm{L}}$ & $11.822^{*}$ & 0.670 & $145.742^{*}$ & 1.174 & $45.082^{*}$ & 1.294 & 0.776 & 0.866 \\
\hline $\mathrm{G}_{\mathrm{Q}} \mathrm{Cd}_{\mathrm{Q}}$ & 8.540 & & $53.556^{*}$ & & $9.481^{*}$ & & 0.107 & \\
\hline $\mathrm{G}_{\mathrm{L}} \mathrm{S}_{\mathrm{L}} \mathrm{Cd}_{\mathrm{L}}$ & 0.721 & 2.304 & 0.827 & $4.878^{*}$ & 0.680 & 0.063 & 0.310 & 2.156 \\
\hline $\mathrm{G}_{\mathrm{L}} \mathrm{S}_{\mathrm{L}} \mathrm{Cd}_{\mathrm{Q}}$ & 0.659 & & 3.074 & & 1.907 & & 0.057 & \\
\hline $\mathrm{G}_{\mathrm{L}} \mathrm{S}_{\mathrm{Q}} \mathrm{Cd}_{\mathrm{L}}$ & & 0.193 & & 0.024 & & 1.557 & & 0.032 \\
\hline $\mathrm{G}_{\mathrm{Q}} \mathrm{S}_{\mathrm{L}} \mathrm{Cd}_{\mathrm{L}}$ & 0.366 & 0.000 & 1.428 & 2.124 & 0.444 & 0.526 & 0.001 & 1.315 \\
\hline $\mathrm{G}_{\mathrm{Q}} \mathrm{S}_{\mathrm{L}} \mathrm{Cd}_{\mathrm{Q}}$ & 0.606 & & 3.969 & & 3.599 & & 0.302 & \\
\hline $\mathrm{G}_{\mathrm{Q}} \mathrm{S}_{\mathrm{Q}} \mathrm{Cd}_{\mathrm{L}}$ & & 0.193 & & 0.457 & & 2.028 & & 1.673 \\
\hline Error (M.S.) & 0.0096 & 0.0088 & 1.6704 & 1.2304 & 0.3675 & 0.2474 & 102.2169 & 72.2136 \\
\hline
\end{tabular}




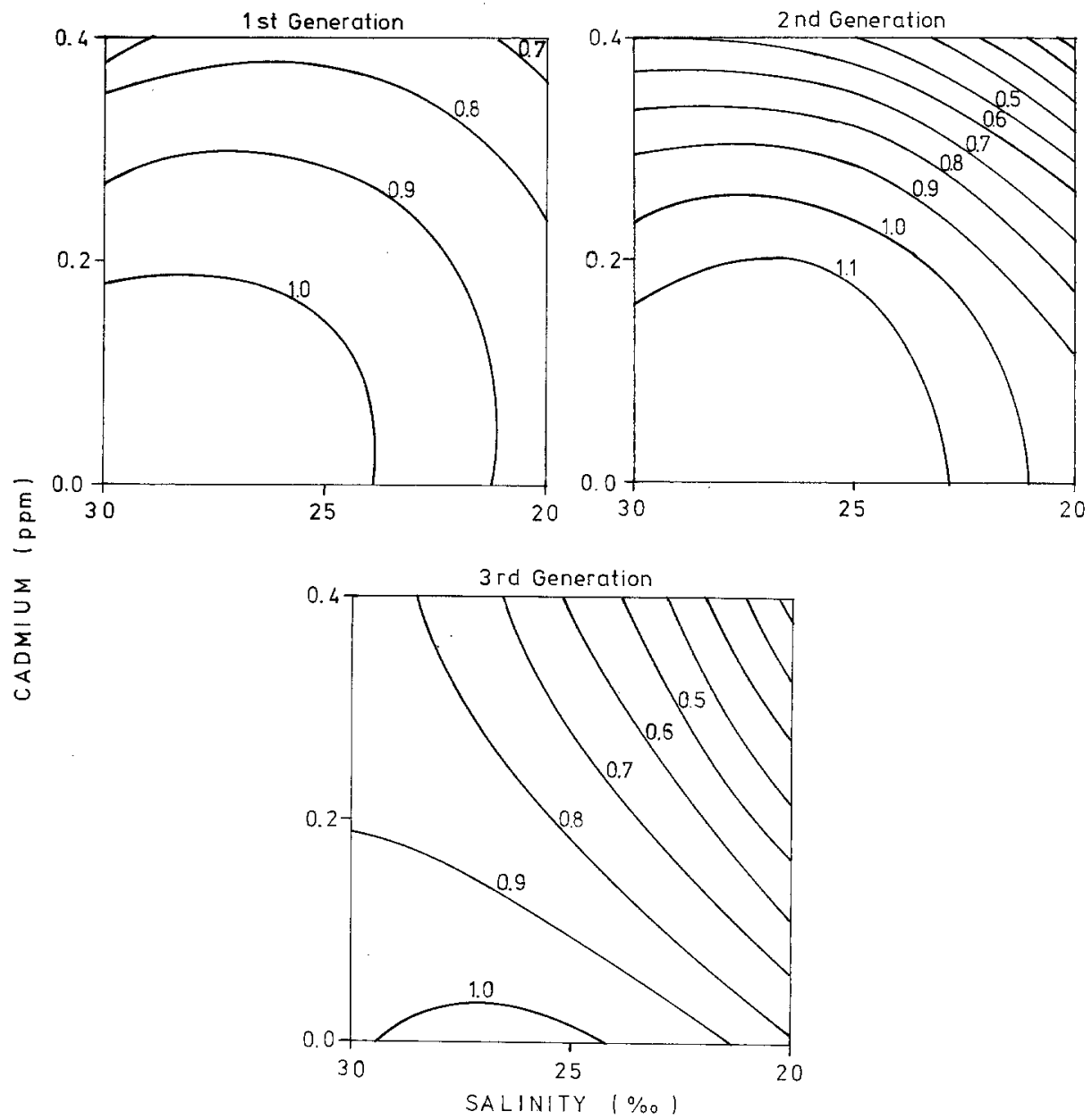

Fig. 4. Response surface contours of individual growth rate of three generations of Ophryotrocha labronica when exposed to various concentrations of salinity and cadmium

(Column B in Table 2) were taken into account. There was also a significant quadratic effect of generation (Column B), i.e. the transmission of the growth-reducing effects over the generations at any level of salinity and cadmium (0.0 and $0.2 \mathrm{ppm})$ tested has a quadratic effect.

Of the three sets of two-way interactions, only generation $\times$ cadmium was statistically significant (Table 2). Significant interaction means either greater than additive (synergistic) or less than additive (antagonistic) effects. The interaction of generation $\times$ cadmium on growth-rate reduction shows a quadratic trend in the transmission along the three generations on both the linear and quadratic components of cadmium. These significant interaction effects appear to be due to two trends (Table 1): (1) A relatively high synergistic effect at $0.4 \mathrm{ppm}$ cadmium in the second generation over the two salinities 30 and $25 \%$, whereas the first and third generations show similar trends but are less affected. (2) The synergistic effect at $0.2 \mathrm{ppm}$ in the third generation is larger 
Table 3. Time to maturity (days) of Ophryotrocha labronica at various combinations of cadmium and salinity of three generations (means of two replicates)

\begin{tabular}{|c|c|c|c|c|c|c|c|c|c|}
\hline \multirow[t]{2}{*}{ Generation } & \multicolumn{9}{|c|}{$\begin{array}{c}\text { Cadmium (ppm) } \\
0.2 \\
\text { Salinity (\%o) }\end{array}$} \\
\hline & 30 & 25 & 20 & 30 & 25 & 20 & 30 & 25 & 20 \\
\hline $1^{\text {st }}$ & 15 & 16 & 16 & 15 & 15 & 17 & 16 & 17 & 17 \\
\hline $2^{\text {nd }}$ & 15 & 15 & 16 & 17 & 15 & 18 & 30 & 30 & - \\
\hline $3^{\text {rd }}$ & 16 & 17 & 17 & 17 & 26 & 24 & 19 & 17 & - \\
\hline
\end{tabular}

when compared with those of the first and second generations over the two salinities 30 and $25 \%$. The significant linear $\times$ linear effect in Column B (Table 2) is due to a synergistic growth suppression in the third generation at $0.2 \mathrm{ppm}$ cadmium over the three salinities tested. The three-factor interactions were not statistically significant.

Response-surface diagrams were plotted at the three successive generations (Fig. 4). A comparison between the variance of the experimental error and the total mean square (Snedecor \& Cochran, 1967) showed that the contours in Figure 4 explained more than $99 \%$ of the variance at first and second generation and $97.4 \%$ at the third generation, indicating that the regression equations gave relatively good fit to the results even when the growth-rate value at $20 \%$ and $0.4 \mathrm{ppm}$ cadmium was set at zero for the second and third generations.

\section{Effects on time to reach maturity}

Table 3 gives the periods needed to reach maturity for the three generations over the factorial design. One should be cautious in drawing detailed conclusions due to the relatively few observations made in the area where the organisms seemed to attain maturity (see Fig. 3). However, Table 3 illustrates that the time to maturity in the first generation does not seem to be highly affected by cadmium concentration or salinity. None of the three generations showed dramatic change in the time to maturity when no cadmium was added to the water. However, the time to maturity at $0.2 \mathrm{ppm}$ cadmium was prolonged in the third generation and greatly prolonged at $0.4 \mathrm{ppm}$ cadmium in the second generation, i.e. much the same tendency as that for the growth rate. This is further illustrated in Table 2 which shows much the same significant effects as for the growth rate with the generation $x$ cadmium having the greatest interacting effect.

The fact that $O$. labronica showed roughly the same significant sources of variance in both the growth rate and the time to reach maturity indicates that the organisms respond to reduced growth rate, within the concentrations tested, by prolonging the time taken to reach maturity.

\section{Effects on size at maturity}

Figure 3 illustrates the decrease in size at maturity of the first generation of $O$. labronica both when the organisms were exposed to lowered salinity $(20 \%)$ and to the highest cadmium concentration (0.4 ppm). However, the size at maturity (Table 4$)$ is 
Table 4. Size at maturity (mean number of segments) of Ophryotrocha labronica at various combinations of cadmium and salinity over three generations (means of two replicates)

\begin{tabular}{|c|c|c|c|c|c|c|c|c|c|}
\hline \multirow[t]{2}{*}{ Generation } & \multicolumn{3}{|c|}{0} & \multicolumn{3}{|c|}{$\begin{array}{c}\text { Cadmium (ppm) } \\
0.2 \\
\text { Salinity }(\%)\end{array}$} & \multicolumn{3}{|c|}{0.4} \\
\hline & 30 & 25 & 20 & 30 & 25 & 20 & 30 & 25 & 20 \\
\hline $1^{\text {st }}$ & 14.1 & 14.2 & 11.8 & 12.2 & 12.2 & 11.4 & 11.3 & 11.2 & 10.2 \\
\hline $2^{\text {nd }}$ & 13.4 & 13.2 & 11.9 & 12.7 & 11.6 & 12.0 & 14.5 & 14.5 & \\
\hline $3^{\text {rd }}$ & 13.9 & 13.6 & 12.0 & 12.4 & 13.0 & 11.7 & 12.6 & 11.2 & \\
\hline
\end{tabular}

reduced from 13-14 segments when no cadmium was added to the water (salinities of 30 and $25 \%$ ), to $12-13$ segments when the organisms were exposed to $0.2 \mathrm{ppm}$ cadmium. This appeared at all the three generations tested.

The three-way analysis of variance (Table 2) shows similar main tendencies for the growth rate and for the time to reach maturity. The quadratic trend on the linear components of cadmium in the transmission of the effects over generations is clearly the most important interacting factor. This interacting factor can be seen in Table 4 as an increase in size at the second generation compared with the first and third generations at a cadmium level of $0.4 \mathrm{ppm}$. This increase is most probably the result of the extremely long period this generation needed to reach maturity when exposed to $0.4 \mathrm{ppm}$ cadmium (Table 3). However, the overall tendency in adding cadmium and varying the salinity was a reduced size at maturity. The fact that both the growth rate and the age and size at maturity showed roughly the same significant effects (Table 2) indicates that the prolongation of the time to reach maturity when the growth rate became reduced is not. great enough to compensate for the effect of the reduction in growth rate.

\section{Effects on reproduction}

Table 5 gives the percent of hatched egg masses for the three generations over the factorial design. The three-way analysis of variance of these data (Table 2) shows that both cadmium and salinity affected reproduction by a decrease in the percentage of egg masses hatched. The main quadratic effect of generation found in the two analyses (A and $B$ in Table 2) was due to a tendency to more successful reproduction in the second

Table 5. Percent hatched egg masses of $O$. labronica at various combinations of cadmium and salinity at the three generations (means of two replicates)

\begin{tabular}{|c|c|c|c|c|c|c|c|c|c|}
\hline \multirow[t]{2}{*}{ Generation } & \multicolumn{3}{|c|}{0} & \multicolumn{3}{|c|}{$\begin{array}{c}\text { Cadmium }(\mathrm{ppm}) \\
0.2 \\
\text { Salinity }(\%)\end{array}$} & \multicolumn{3}{|c|}{0.4} \\
\hline & 30 & 25 & 20 & 30 & 25 & 20 & 30 & 25 & 20 \\
\hline $1^{\mathrm{st}}$ & 86.1 & 83.9 & 56.8 & 75.0 & 73.5 & 59.1 & 45.0 & 39.8 & 0.0 \\
\hline $2^{\text {nd }}$ & 100.0 & 95.8 & 84.7 & 87.5 & 87.1 & 56.1 & 72.5 & 59.1 & \\
\hline $3^{\text {rd }}$ & 91.3 & 86.7 & 72.2 & 82.6 & 68.9 & 51.9 & 61.4 & 42.5 & \\
\hline
\end{tabular}


generation than in the first and third generations. None of the two- or three-factor interactions were significant. However, the mean square error term of the analyses (see Table 2) was a factor 50-100 times greater than for the other analyses and illustrates the difficulties in measuring this parameter.

\section{DISCUSSION}

This work, together with that of others (Åkesson, 1970, 1975; Jernløv et al., 1972; Saliba \& Ahsanullah, 1973), has'shown that analysis of effects of chemicals on growth processes of Ophryotrocha labronica is a sensitive technique for assessment of pollutant effects on this organism. The relatively small error terms in the data from the growth processes in this work reflect that the values are fairly reproducible. However, for the percent egg masses hatched, one should be cautious in drawing conclusions due to the large variation between the replicates. This work has also shown the importance of running the long-term experiments over several generations and examining the effects of the pollutant on more than one growth parameter.

The toxicity of cadmium to $O$. labronica with a $48-\mathrm{h} \mathrm{LC}_{50}$-value of $4 \mathrm{ppm}$ was similar to that measured by Brown \& Ahsanullah (1971) in the same species, and also to that reported by Reish \& Carr (1978) for the related species $O$. diadema. However, the former studies were on single variables. As the present study shows that the toxicity of cadmium increased (additive effect) with decreasing salinity and was fatal at $0.4 \mathrm{ppm}$ and $20 \% \mathrm{~S}$ where the organisms were not able to reproduce successfully, it is clear that the combined effects of salinity and cadmium must be considered. The fact that $O$. labronica is affected at $20 \% \mathrm{~S}$, when no cadmium is added to the water (e.g. reduced growth rate, Fig. 3), indicates that the organism is under physiological stress in attempting to regulate its body fluid in a hyposmotic environment. Additional external stress in the form of cadmium (0.4 ppm) then becomes fatal. Similarly, Jones (1975) in experiments with cadmium found that a decrease in salinity caused an increase in mortality of some estuarine isopods, and in experiments with herring embryos (Clupea harengus), von Westernhagen et al. (1974) found that the deleterious affects of cadmium-contaminated water were more pronounced at low salinity. Accumulation of cadmium via water by the fiddler crab Uca pugilator has also been shown to be higher at reduced salinities than in normal seawater (O'Hara, 1973).

Cadmium has been shown to inhibit or depress the activity of a large number of enzymes and other physiological processes (see review by Vallee \& Ulmer, 1972). The fact that small cadmium concentrations have a growth-suppression effect and increase the time to maturity of $O$. labronica indicates that developmental processes are affected. Similarly growth-rate suppression on $O$. labronica has also been reported when exposed to other pollutants. Thus, Brown \& Ahsanullah (1971) found significant suppression of growth rate at 0.1 and $0.05 \mathrm{ppm}$ copper. The depression of the growth processes in $O$. labronica when exposed to cadmium seems to be only partly compensated by a prolonged time needed to reach maturity and results show that the size at maturity is also affected.

Cadmium concentrations of $0.2 \mathrm{ppm}$ at 30 and $25 \% \mathrm{~S}$ affected neither growth rate nor the time to maturity in the first and second generations. However, the size at maturity decreased. This indicates an effect of $0.2 \mathrm{ppm}$ cadmium on the "lag" phase (first phase in 
Fig. 1) which therefore seems more sensitive to small cadmium concentrations than both the growth rate (second phase) and the time to maturity. The effect on this "lag" phase could be due to either a longer "lag" period before the second phase (growth proper) starts, or a decrease of presumptive growth in this "lag" phase, or a combination of these effects. Rosenberg \& Costlow (1976) reported that cadmium induced a significantly longer duration of larval development in the mud crab Rhithropanopeus harrisii. However, the relatively few observations made between the time when the egg masses hatch to when the second phase starts makes it difficult to assess whether the same occurs in $O$. labronica. The fact that the animals are most sensitive to small cadmium concentrations when in the "lag" phase is further supported by the results at $0.4 \mathrm{ppm}$ cadmium at $20 \% \mathrm{~S}$ where the second generation did not hatch or died soon after hatching.

The toxicity of cadmium changed significantly over the three generations examined. The fact that increased toxicity of cadmium was observed at the third generation when exposed to $0.2 \mathrm{ppm}$ and at the second generation when exposed to $0.4 \mathrm{ppm}$ cadmium seems to be due to an increased effect of the toxicity of cadmium through time (generation). At small concentrations $(0.2 \mathrm{ppm})$ it takes longer (third generation) before the increased effects become significant than when the organisms are exposed to higher concentrations $(0.4 \mathrm{ppm})$. Here the increased effects become significant earlier (second generation). Klöckner (1979) reported that cadmium content of adult Ophryotrocha diadema individuals of three consecutive generations subjected to permanent contamination did not increase from the first to the third generation. This indicates that the increased effects of cadmium over the generations observed in this study is due to decreased tolerance to cadmium levels rather than increased accumulation. Similarly, Saliba \& Ahsanullah (1973) reported that the brine shrimp Artemia salina acquired an increased tolerance to copper after exposure to low concentrations for two to three weeks, but this tolerance was less for the second and third generations than for the first generation.

However, $O$. labronica showed increased growth at $0.4 \mathrm{ppm}$ cadmium from the second to the third generation. This is against the trend of reduced growth over generations for the three other data sets, namely $0.2 \mathrm{ppm}$ cadmium at all the three salinities. Increased growth from the second to third generation at $0.4 \mathrm{ppm}$ for both salinities 30 and $25 \%$ may indicate adaptation to the cadmium-contaminated water.

It is possible that there is a threshold for toxic effects (combination of cadmium and salinity) which must be reached before adaptation mechanisms are initiated. At $0.4 \mathrm{ppm}$ the threshold is reached, adaptation processes begin and growth rate rises again from the second to third generation. According to this hypothesis at $0.2 \mathrm{ppm}$ the threshold was not yet reached; growth rate will rise only during following generations when the threshold is attained and the adaptive mechanisms are operative.

However, it is possible that the physiological stress exerted on the organisms at $20 \% \mathrm{~S}$ is so great that such adaptation to $0.2 \mathrm{ppm}$ cadmium is not employed and in following generations the toxicity will continue to increase to a fatal level.

Change in the ability to adapt to toxic metals has also been reported in experiments with the archiannelid Dinophilus gyrociliatus exposed to different concentrations of cadmium and mercury (Røed, 1979). At $30 \% \mathrm{~S}$ adaptation to cadmium and mercury acting together was observed, but at reduced salinity $(25 \%)$ the adaptation mechanisms seemed to be neutralized. 
Bryan \& Hummerstone (1971) reported adaptation to increased concentration of heavy metals in Nereis diversicolor from an estuary in southwest England contaminated with mining wastes, and Bryan (1974) concluded that this adaptation was most likely genetically controlled. The work here on $O$. labronica has probably not covered sufficient generations to allow the establishment of any genetic adaptation and the adaptive trends shown are probably physiologically controlled.

Acknowledgements. I wish to thank Professor John S. Gray for helping throughout this work. Financial support was gratefully received from the Norwegian Research Council for Science and the Humanities.

\section{LITERATURE CITED}

Ákesson, B., 1970. Ophryotrocha labronica as test animal for the study of marine pollution. Helgoländer wiss. Meeresunters. 20, 293-303.

Åkesson, B., 1975. Bioassay studies with polychaetes of the genus Ophryotrocha as test animals. In: Sublethal effects of toxic chemicals on aquatic animals. Ed. by J. H. Koeman \& J. J. T. W. A. Strike. Elsevier, Amsterdam, 234 pp.

Brown, B. \& Ahsanullah, A., 1971. Effect of heavy metals on mortality and growth. - Mar. Pollut. Bull., 2, 182-187.

Bryan, G. W., 1974. Adaptation of an estuarine polychaete to sediments containing high concentrations of heavy metals. In: Pollution and physiology of marine organisms. Ed, by F. J. Vernberg \& W. B. Vernberg. Acad. Press, London,123-135.

Bryan, G. W. \& Hummerstone, L. G., 1971. Adaptation of the polychaete Nereis diversicolor to estuarine sediments containing high concentrations of heavy metals. - J. mar. biol. Ass. U. K. $51,845-863$.

Davies, J. S., 1963. The design and analysis of industrial experiments. Oliver \& Boyd, London, $673 \mathrm{pp}$.

Fisher, R. A. \& Yates, F., 1963. Statistical tables for biological, agricultural and medical research. Longman, London, $146 \mathrm{pp}$.

Gray, J. S. \& Ventilla, R. E., 1971. Pollution effects on micro- and meiofauna of sand. - Mar. Pollut. Bull. 2, 39-43.

Jernløv, A., Rosenberg, R. \& Jensen, S., 1972. Biological effects and physical properties in the marine environment of aliphatic chlorinated by-products from vinyl chloride production. - Wat. Res. 6, 1181-1191.

Jones, M. B., 1975. Synergistic effects of salinity, temperature and heavy metals on mortality and osmoregulation in marine and estuarine isopods (Crustacea). - Mar. Biol. 30, 13-20.

Klöckner, K., 1979. Uptake and accumulation of cadmium by Ophryotrocha diadema (Polychaeta).Mar. Ecol, Prog. Ser. 1, 71-76.

O'Hara, J., 1973. Cadmium uptake by fiddler crabs exposed to temperature and salinity stress. - J. Fish. Res. Bd Can. 30, 846-848.

Perkins, E. J., 1974. The biology of estuaries and coastal waters. Acad. Press, London, 678 pp.

Preston, A., 1973. Heavy metals in British waters. - Nature, London, 242, 95-97.

Reish, D. J. \& Carr, R. S., 1978. The effect of heavy metals on survival, reproduction, development, and life cycles for two species of polychaetous annelids. - Mar. Pollut. Bull. 9 (1), 24-27.

Rosenberg, R. \& Costlow, J. D., Jr., 1976. Synergistic effects of cadmium and salinity combined with constant and cycling temperatures on the larval development of two estuarine crab species. Mar. Biol. 38, 291-303.

Røed, K. H., 1979. The effects of interacting salinity, cadmium, and mercury on population growth of an archiannelid, Dinophilus gyrociliatus. - Sarsia 64, 245-252.

Saliba, L. J. \& Ahsanullah, M., 1973. Acclimation and tolerance of Artemia salina and Ophryotrocha labronica to copper sulphate. - Mar. Biol. 23, 297-302.

Snedecor, G. W. \& Cochran, W. G, 1967. Statistical methods. The Iowa State Univ. Press, Ames, Iowa, $593 \mathrm{pp}$. 
Vallee, B. L. \& Ulmer, D. D., 1972. Biochemical effects of mercury, cadmium, and lead. - A. Rev. Biochem. 41, 91-128.

Waldichuk, M., 1974. Some biological concerns in heavy metal pollution. In: Pollution and physiology of marine organisms. Ed. by F. J. Vernberg \& W. B. Vernberg. Acad. Press, London, $492 \mathrm{pp}$.

Westernhagen, H. von, Rosenthal, H. \& Sperling, K.-R., 1974. Combined effects of cadmium and salinity on development and survival of herring eggs. - Helgoländer wiss. Meeresunters. 26, 416-433. 